\title{
The impact of increasing temperatures in transition zones on energy demand
}

\author{
T. Kansara
}

UCL Energy Institute, London, UK

\begin{abstract}
This paper describes the transitional zones of modern buildings and the impact of raising their temperature. A transitional zone is described as none steady-state spaces like entrance lobbies, corridors, lift-lobbies and landings, which allow occupants to transition through to more steady-state spaces. This paper presents the results of a dynamic simulation, where a typical case study building is used for an intervention of $1-5^{\circ} \mathrm{C}$ increases in indoor temperature on energy demand. The results show raising the temperature in the transitional zones can result in a saving of $0.63 \%$ per ${ }^{\circ} \mathrm{C}$ reduction of cooling for the whole building. The recommendation of this paper is to investigate a broadening of the thermal comfort parameters of these communal areas not serviced by the ASHRAE-55: 2-13, or any other standard, in order to identify the potential for reducing electricity used for cooling. Applying sensible engineering design load calculations will ensure comfort conditions and energy use are treated separately to occupied zones.
\end{abstract}

\section{Keywords: Transition Zones, Thermal Comfort, Energy Demand Reduction}

\section{Introduction}

The increase in urban development has resulted in growing energy demand because on average buildings use $65 \%$ of their total electricity on cooling [1]. There is growing concern of blackouts as the urban population increases faster than some can supply electricity [2-6]. The focus towards more passive measures to reduce a significant portion of electricity that is used in spaces that are not occupied has yet to surface. At present it is difficult to determine the exact energy use of buildings as it is difficult to know indoor electricity use.

Indoor electricity demands for cooling - may be reduced by up to $67 \%$ if chillers are used efficiently [7-9]. Literature suggests they are not working as effectively as they could be, which is due to chillers not being sequenced and operated correctly [7][9-15].

The lack in cooling strategy or policy to direct a reduction in electricity demand means buildings are cooled throughout the year with no variation in thermostat settings. There exists an opportunity to model the impacts of raising the temperature in areas that are not constantly occupied, lacking in current literature and standards is the transition zone, non-steady state

${ }^{*}$ Corresponding author. Tel.: +442076792000

E-mail: tia.kansara@gmail.com

(C) 2017 International Association for Sharing Knowledge and Sustainability

DOI: $10.5383 /$ ijtee. 14.01 .002 areas, which call for procedures to design for occupants transitioning through from the outside - in.

These transitional zones are described by Hwang et al. [16] as a place where the physical environment bridges the interior and exterior space - a modified climate characterized by highly variable physical conditions [17]. The question arises thus, what are the criteria for the design energy reduction in these areas?

Although the aim of air conditioning is to help create thermally neutral environments, the result is a heavy attachment to indoor temperatures that are often not applicable to the external climate. Under question are the transition zones that occupy neither the outside nor the inside. Keeping open-plan spaces, increasing ventilation and decreasing solar insolation by shading are techniques to reduce energy demand. In modern buildings over-specified HVAC systems do this, not mindful to the rising costs of energy.

The following review determines the use of transitional zones. It then evaluates literature on energy demand reduction using a stepped decrease in cooling demand by a dynamic simulation model. 


\section{Literature Review}

\subsection{Transitional Zones}

Upon entry into the building, the entrance transition zone is the first space the occupant passes through, see Fig. 1. Communal areas inside the building comprise of lobbies, stairways, lift areas, reception areas and corridors. They help occupants move from one steady-state environment to another. The transition zones are currently designed with identical thermal comfort parameters and are cooled like steady-state environments.

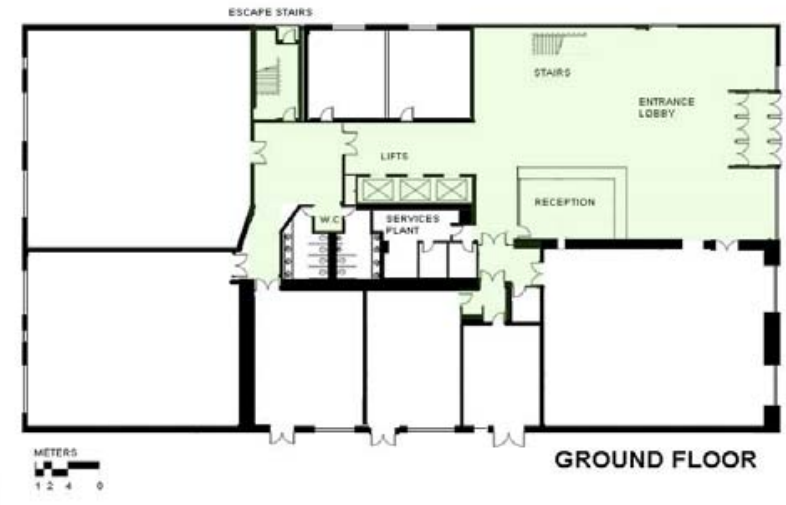

Fig. 1: Ground floor plan of transition zone in green spaces

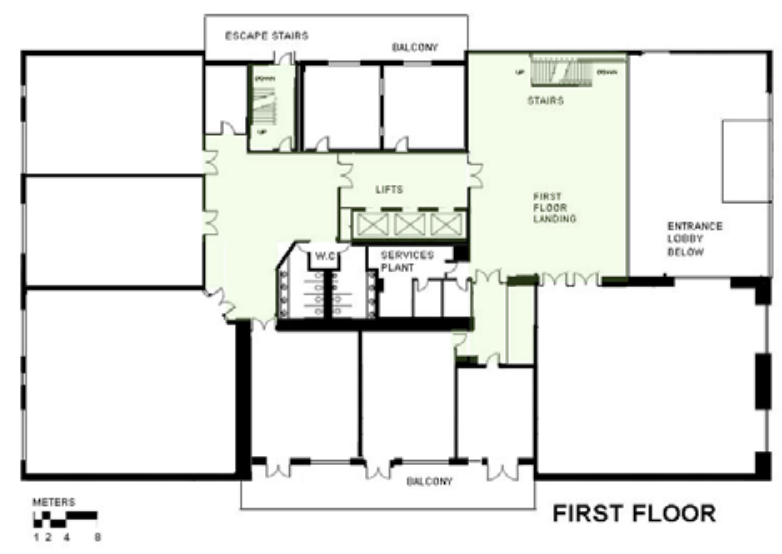

Fig. 2: First floor plan of transition zone in green spaces

There is an opportunity to test whether the thermal comfort parameters in these spaces may be widened to provide slightly warmer environments without forfeiting comfort, particularly when transition zones are not continuously occupied. A decrease in cooling could lead to potential savings of electricity. Nicol et al. suggest a $10 \%$ saving may be made for every one-degree reduction of heating in the UK [18]. There is an opportunity to research what a one-degree reduction in cooling may have on the built environment.
The closest research on the neutral temperatures reached for four groups under assessment by Jitkhajornwanich and Pitts in a variety of transitional zones in Bangkok [19]. They report neutral temperatures that are comfortable for these groups and also suggest the use of air-conditioned and naturally ventilated transitional zones for testing [19].

\subsection{Opportunities for energy demand reduction in} transition zones

There appears to be a lack of investigation of the building stock to gauge what measures may be taken to improve building energy use without retrofitting, such as changing the comfort settings. This is done by intervening with the air conditioning, and utilising the final point of Roaf et al.'s suggestions to adjust lifestyles indoors [20].

Transitional spaces use three times the energy per unit area of non-transitional environments in open-areas inside buildings like atria exposed to the external environment [21-22] Barbhuiya, et al. (2013) suggest, in their research on UK educational buildings, that draft-proofing the gap above the front door can save $13 \%$ of the energy use of the building [23]. A large number of measures have been applied to seal buildings to maintain such factors like cooling efficiency. Buildings increasingly have a variety of cooling mechanisms. Some buildings have split-units and others have either a central cooling system that distributes cool air throughout the building or a district cooling system that connects buildings. As each building differs in cooling, most buildings retain a central core of communal space that is governed by the owner of the building. Access to these common areas provides an opportunity to conduct experiments - to adapt energy saving measures within existing building by zoning cooling opportunities. The transition spaces are accessible for experimentation inside the building as they are shared by all occupants equally, unless continuously occupied by receptionists or security staff. Humphreys et al. (2010) have shown that an increase in temperature indoors in warm climates is acceptable by occupants [24]. At present transition spaces are not controlled as separate areas to the rest of the building, but as Pitts suggests [25], there is an opportunity to investigate ways to reduce energy consumption by examining transition zones by highlighting the differences between entrances, circulation and permanent spaces. This may provide insights into occupant expectations of comfort inside these spaces.

During the summer, occupants may transition from an external high heat-stress condition to a cooled environment. The time spent in the entrance may have a direct impact on the thermal comfort of occupants as their bodies adjust to the internal environment and yet they are cooled to identical specifications of other permanently-occupied areas [25].

Ojima and Miura's study looked at the heating of a mall in Tokyo [22]. The internal temperature below ground showed an average temperature of $25-27^{\circ} \mathrm{C}$. Although this assessment took place over four 3-day periods in the months of January, June, August and October, it was unclear whether the transition zone underground and on the ground floor were of the same size. The analysis showed the difference in the energy used to cool buildings in a variety of cities in Japan. No interventions took place to estimate how much energy changing the internal temperature, could save. This opens possibilities for the assessment of building communal areas. 
The potential energy savings for changing temperatures in the transition spaces have been outlined below in a model generated to understand the potential energy saving from buildings:

"The results clearly show substantial opportunity for energy saving which can be quantified in the region of $6 \%$ in winter if set point control temperatures are allowed to vary by $\pm 3^{\circ} \mathrm{C}$ and $10 \%$ if $\mathrm{a} \pm 5^{\circ} \mathrm{C}$ variation is permitted.[26]"

This argument suggests a relaxation of comfort standards in the transition spaces, where the variation between the outdoors and indoors may be as much as $30^{\circ} \mathrm{C}$. Saleh \& Pitts have not tried changing the temperature in these zones to assess the impact of this on occupant satisfaction and energy use. The entrance transition space thus provides a unique zone to investigate a potential widening of setpoint temperatures.

Current Energy Codes do not contain a thermal zone may or may not include transition zones as a separate area. Design engineers when establishing the zones do not have this information, which suggests there is a lack of regulation on the specific design of these spaces as they are open to interpretation ${ }^{27}$. The transition zones are controlled by building operators and managers in many buildings, as such, the ability to implement modifications does not require complex negotiations with residents. A potential exists to introduce an acclimatisation zone before occupants move from the entrance to the rest of the building.

A well-established body of research measures the indoor environment, by definition, as a steady state: where the internal physical parameters of measures (temperature, relative humidity, air flow) are constant with time. However, a growing interest in the immediate impacts on occupants upon-entry into a building, or in the various connecting spaces between steady-state environments, suggest there is room to investigate the impact of transition zones on the occupant. Little is known about these in terms of their individual thermal comfort but there are a few examples of estimated and actual studies completed, which will be reviewed in this paper.

The transition zones prepare occupants for new thermal sensations ahead [26-28]. The modification of expectations aims to reduce thermal shock or discomfort. Based on thermal sense, occupants are delighted by the function of architecture that prepares them for the next thermal experience [29]. This sense, separate from the others, enjoys a range of temperatures - in contrast to one another.

Acclimatisation is the ability of a person to adapt their body to a new environment ${ }^{30}$. It is known as Acclimation when referring to acclimatisation in laboratories [30]. There are two impacts of acclimatisation; the first is physiological change, which occurs naturally with increased exposure to hot environments, the second is a behavioural response. This may be because of a reduction in the level of activity and perhaps changes in clothing and diet ${ }^{30}$.

Occupants often pass through the transition zones and enter more sedentary environments from the hot environment outdoors. In some cases, where the indoor temperature and relative humidity are high, the body experiences a greatly lessened rate of perspiration and the blood vessels recede from the skin surface. For someone who has left the hot outdoor environment, the conditioned transition areas can be too cool for comfort. Thus a greater sense of discomfort results, as evaporation cannot decrease instantly, and the body does not adjust to the temperature quick enough to balance the body's heat production and loss. The BS EN ISO 7730: 2005 recommends a higher temperature and lower humidity for these small spaces.

Clause 8 of the BS EN ISO 7730: 2005 illustrates the sudden change in the thermal conditions upon entry due to step changes in temperature, humidity, activity or clothing, may be given the following characteristics:

- A step-change of operative temperature is felt instantaneously.

- After an up-step in operative temperature, the new steady-state thermal sensation is experienced immediately, i.e. the PMV-PPD can be used to predict comfort.

- Following a down-step in operative temperature, the thermal sensation drops at first to a level beneath the one predicted by PMV, then increases and reaches the steady-state level after approximately $30 \mathrm{~min}$, i.e. the PMV-PPD predicts values that are too high for the first $30 \mathrm{~min}$.

Nicol et al. suggest buildings are composed of many different zones [18]. What may be true for a room facing one direction may be false for another room in the same building facing the opposite direction ${ }^{18}$. This leads to questions whether having a uniform steady-state for the different zones in buildings is the most intelligent manner to treat buildings.

Upon entry into the building, proper walls, according to the design regulations of Building Regulations of a "transmittance" to heat (or U-value) of 0.25 , are seldom seen. The 'glass-box' double-glazed buildings often have 10 times this U-value - such that, protection from the 'indoor greenhouse effect' is experienced only through over-specified mechanical cooling. In turn this creates an upward economic cost of maintenance due to the cleaning of these every 3 months (from dust and humidity sludge in machines), replacement every 10/20 years (from over work in the summer) and health costs related to the infections from mould and Legionella ${ }^{20}$.

\section{Methodology}

Dynamic Simulation Modelling (DSM) is used to model an estimation of the energy saving potential of widening the comfort zone in transition spaces. This section describes how DSM was used to understand a building using its occupancy schedules, mechanical drawings with building information to mimic its energy use. The model was used to simulate a variety of changes to broaden the comfort parameters of the building to simulate what affects these will have on the building.

An energy model of a typical building in Abu Dhabi, UAE (Case 01) was created to understand the impact of increased cooling setpoint temperatures in transitional spaces on overall building energy consumption/Transitional zones, where occupants move between occupied zones, such as lobbies, stairs and circulation spaces, are mapped in the model. Case 01 is a mixed-use tower block, comprising of retail shops, offices and residential spaces. 
The current setpoint temperature for transition zones in Case 01 is $21^{\circ} \mathrm{C}$. By creating a building energy model of Case 01 , the transitional zone cooling setpoints can be systematically altered and the resultant impact upon energy consumption measured. Annual energy savings are considered at each setpoint and individual transitional zones looked at over a monthly period, using August 2011 as a base case. The base case is compared to August 2012 where the weather data for both months has been prepared using Meteonorm V7. EnergyPlus Version 8.3.0.001 is an open source software and DesignBuilder Version 4.5.0.178 is another commercial product used to model Case 01's energy use in the transition zone. EnergyPlus is a widely used open source program for energy analysis and thermal load simulation, which is supported by the US Department of Energy. EnergyPlus is used to calculate heating and cooling loads for thermal control and energy consumption. This is possible through setpoint, HVAC system, coil load and primary plant equipment design and simulation within the tool. The benefits of using EnergyPlus outweigh its limitations, according to the ASHRAE Standard 140, which compares the predictive capacity of different simulation programs [31].

DesignBuilder is a UK commercial tool, which acts as a graphical interface for EnergyPlus. Its use here was justified for its robustness, availability and practical application for analysing the setpoint changes in the transitional areas. All Input/Output references were taken from the user documentation provided by EnergyPlus. The weather files were obtained for Abu Dhabi and converted into EPW format.

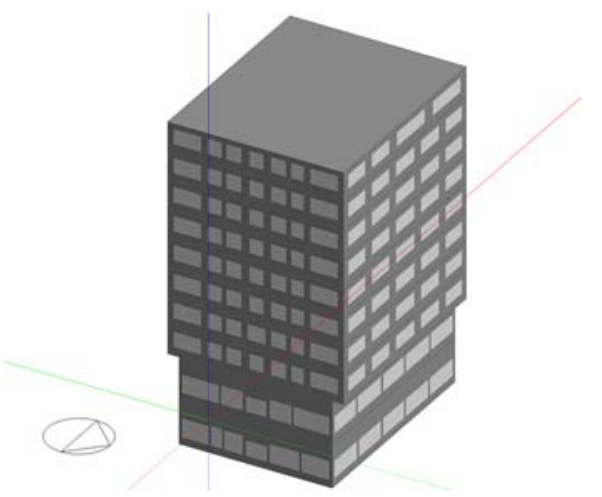

Fig. 3: Case 01 energy model visualisation

The energy model has been created using information from as-built mechanical, electrical drawings, schedules and information provided by the facilities management team. Glazing was set at a $40 \%$ the window to wall ratio of the actual building. Any lack of data was substituted using engineering best practice with typical space and construction data taken from ASHRAE 90.1, 62.1 and Design Builder standard templates. Geometry was modelled from a set of toscale mechanical GA (General Arrangement) drawings and measured using Bluebeam Revu. Floor plans were then sketched into DesignBuilder using the block geometry creator and extruded. The ground and mezzanine floor to ceiling heights were set at $4.5 \mathrm{~m}$, while the remainder of floors were set to $3 \mathrm{~m}$.

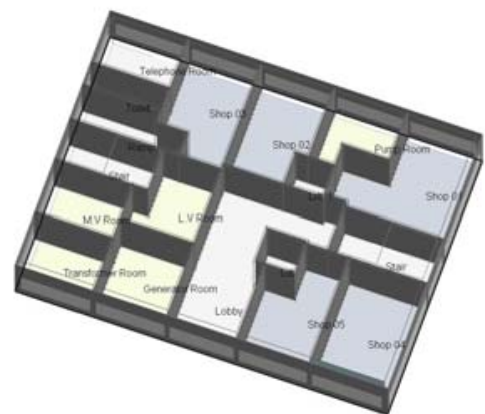

Fig. 4: Axionometric view of ground floor within DesignBuilder

Schedules of Case 01 operation were mimicked using actual occupancy in all spaces within the building from the reconnaissance. The operational timings were used to calculate when its occupancy levels impacted the operation of the building. Table 1 lists the occupancy schedules for the different spaces indoors.

Table 1: Occupancy schedules for Case 01

\begin{tabular}{|l|l|}
\hline Space & Occupancy Schedules \\
\hline Retail & $8 \mathrm{am}-8 \mathrm{pm}$ \\
\hline Offices & $8 \mathrm{am}-4 \mathrm{pm}$ \\
\hline Residences & $\begin{array}{l}6 \mathrm{pm}-7 \mathrm{am} \quad(100 \%) \quad 7- \\
\mathrm{am}-6 \mathrm{pm}(50 \%)\end{array}$ \\
\hline
\end{tabular}

The model was run for 2012 to understand what saving potential there was in comparison to 2011. Annual weather data for 2011 and 2012 was collected from OMAA weather station at $\mathrm{Abu}$ Dhabi International Airport. These were helpful in adjusting the heat gains that may occur from the external climate. Lighting gains were applied using ASHRAE 90.1:2010 data based on zone type. Similarly, occupant gains were taken from the ASHRAE HVAC applications handbook where the majority of spaces use $75 \mathrm{~W}$ sensible and 55W latent gains (standing, light work, walking). The actual occupant gains were calculated using these values and the occupancy schedules. Equipment loads were taken for standard Abu Dhabi templates. The equipment gains were also based on zone types.

The majority of cooled spaces were modelled with cooling setpoints of $21^{\circ}$ and set-back temperatures of $28^{\circ}$ when unoccupied. The transition zones maintained their cooling setpoints continually for each simulation with no set-back condition. Transition zones were straightforward to model, as there was little activity within them and no additional equipment or lighting gains. The setpoint characteristics also remained constant throughout the day. The cooling setpoints of transition zones were changed with each new simulation, increasing the cooling setpoint by $1^{\circ} \mathrm{C}$ each time (maximum $5^{\circ} \mathrm{C}$ ). All other spaces in the building maintained the same setpoint behaviour for all simulations. This process was repeated using weather data from 2011 and 2012. The staircases were modelled using a hole which covered $50 \%$ of 
the floor slab between levels so that both free heat transfer and thermal mass (the staircase itself) were accounted for. The spaces were not merged so that cooling loads for individual floors could be recorded.

\section{Results and Discussion}

The annual total energy saving of $3.12 \%$, visible in potential annual savings, gives a reasonable indication of what can be expected by increasing temperature setpoints in transitional spaces in Case 01.The results provide a clear indication that there is a positive and significant impact on total building energy consumption from increasing transitional space cooling setpoint temperatures, especially in a climate that depends heavily upon air conditioning for occupant comfort. Fig. 5 and Fig 6 show clear downward trends of individual lobby and staircase energy usage with increased setpoints for 2011 and 2012. At individual zone level savings are minor, however when applied across all transition zones the energy savings account for a sizeable measure of annual energy consumption, an average of $0.62 \%$ per ${ }^{\circ} \mathrm{C}$ increase per annum. With an annual overall decrease of $3.12 \%$ after a $5^{\circ} \mathrm{C}$ rise.

Table 2: Annual energy saving percentage against $21^{\circ} \mathrm{C}$ setpoint

\begin{tabular}{|l|l|l|}
\hline Temp. & $\begin{array}{l}\text { Energy per Total } \\
\text { Building Area } \\
\left(\mathrm{kWh} / \mathrm{m}^{2} / \text { annum }\right)\end{array}$ & $\begin{array}{l}\text { Energy Saving Against 21 } \\
\text { Setpoint (\%) }\end{array}$ \\
\hline $21^{\circ} \mathrm{C}$ & 351.7 & - \\
\hline $22^{\circ} \mathrm{C}$ & 350.1 & 0.45 \\
\hline $23^{\circ} \mathrm{C}$ & 347.88 & 1.09 \\
\hline $24^{\circ} \mathrm{C}$ & 345.62 & 1.73 \\
\hline $25^{\circ} \mathrm{C}$ & 343.19 & 2.42 \\
\hline $26^{\circ} \mathrm{C}$ & 340.73 & 3.12 \\
\hline
\end{tabular}

The energy consumption predicted by the model is likely to differ from the actual building as DesignBuilder operates under the assumption that the plant will be perfectly maintained and operated by the users as the designers intended. This is rarely the case. Slight differences in energy usage were seen between 2011 and 2012, as would be expected from year to year.

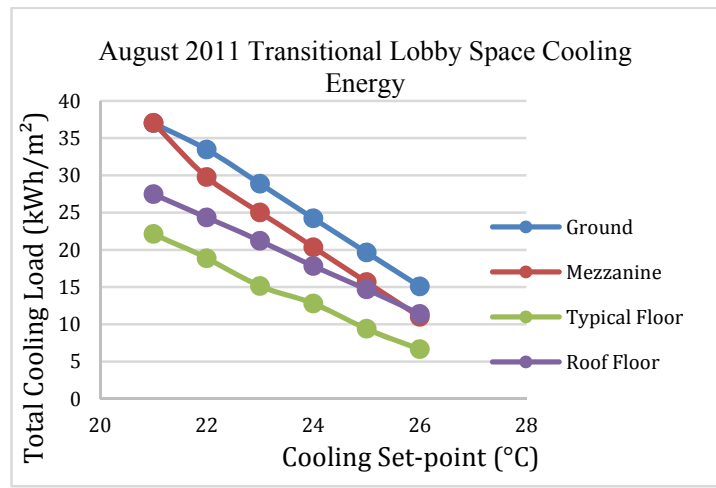

Fig. 5: Transitional lobby space total cooling energy vs cooling setpoint

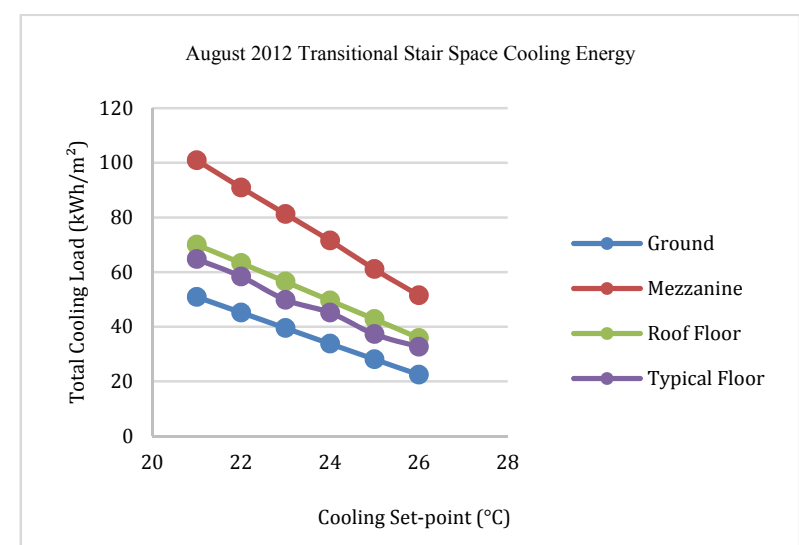

Fig. 6: Transitional stair space total cooling energy vs cooling setpoint

Case 01 mean transition zone temperature in August 2011 was $25.67^{\circ} \mathrm{C}$, the actual energy use during August 2011 was $686 \mathrm{kWh} / \mathrm{m}^{2}$ (1883 $\mathrm{kWh}$ in total during the month). Energy usage values have been normalized by floor area, giving $\mathrm{kWh} / \mathrm{m}^{2}$. This way results across similar spaces can be compared. Likewise, normalized annual energy figures give an average usage per meter squared over an entire year so buildings of similar types can be compared.

The cooling energy use data of individual lobbies over August is not directly comparable to the annual energy consumption figures. However, the two sets of data show the same reduction in transition zone energy consumption with changing set-point temperature.

According to the cooling energy simulation results for August 2011 , for a mean transition zone temperature of $25.67^{\circ} \mathrm{C}$, a mid-point estimation of the energy use by simulation may suggest up to $1,185.5 \mathrm{kWh} / \mathrm{m}^{2}$ for the transition zones in Case 01 . The simulation shows the energy use to be much more than the actual energy used in these spaces during the base case study.

\section{Conclusion}

Based on an annual simulation with a setpoint increase of $5^{\circ} \mathrm{C}$ $\left(21-26^{\circ} \mathrm{C}\right)$ and an energy cost of 38 fils $/ \mathrm{kWh}$, an annual theoretical cost saving of 13,300 AED ( $£ 2432$ ) per annum could be made. Using the same figures a potential carbon saving of $30,000 \mathrm{kgCO}_{2}$ per annum is achievable based on an electrical grid carbon factor of $0.94 \mathrm{kgCO}_{2} / \mathrm{kWh}$. This saving assumes that the building owners have the equipment available to raise the transitional zone temperatures by $5^{\circ} \mathrm{C}$. Applying these hypothetical savings to the total building stock in Abu Dhabi gives savings that will be sufficiently high that the government may decide to investigate the potential saving further.

\section{References}

1. Regulation and Supervision Bureau. Annual Report 2012. (2012). at $<$ http://www.rsb.gov.ae/uploads/AnnualReport2012. pdf $>$ 
2. Kakande, Y. Businesses tally Sharjah blackout toll. (2010). at $<$ www.thenational.ae $>$

3. Mariam, B. \& Serkal, M. Al. Residents battle heat while Sharjah blackout continues. (2009). at $<$ www.gulfnews.com>

4. Khaleej. Sharjah National Paints area faces blackout. (2014). at <www.khaleejtimes.com>

5. Staff, C. W. Sharjah blackout : worker dies as power cut endures. (2010). at $<$ www.constructionweekonline.com>

6. Reuters. Blackouts threaten UAE as summer temp soars. (2011). at <www.arabianbusiness.com>

7. Xue, X., Wang, S., Yan, C. \& Cui, B. A fast chiller power demand response control strategy for buildings connected to smart grid. Appl. Energy 137, 77-87 (2015)

8. Bannister, P. Why Good Buildings Go Bad, While Some Are Just Born That Way. Ecolibrium, J. Aust. Inst. Refrig. AC Heat. 24-32 (2009). at $<\mathrm{http} / /$ scholar.google.com/scholar?hl=en\&btnG $=\mathrm{Se}$ arch\&q=intitle:Why+good+buildings + go + bad + while + some+are+just+born+that+way\#0>

9. Piper, J. 5 Threats to Chiller Efficiency. Facilitiesnet (2003).

$<\mathrm{http} / /$ www.facilitiesnet.com/hvac/article/5-

Threats-to-Chiller-Efficiency--1893\#>

10. Chen, C. L., Chang, Y. C. \& Chan, T. S. Applying smart models for energy saving in optimal chiller loading. Energy Build. 68, 364-371 (2014).

11. Yu, F. W. \& Chan, K. T. Chiller system performance benchmark by data envelopment analysis. Int. J. Refrig. 35, 1815-1823 (2012).

12. Saidur, R., Hasanuzzaman, M., Mahlia, T. M. I., Rahim, N. a. \& Mohammed, H. a. Chillers energy consumption, energy savings and emission analysis in an institutional buildings. Energy 36, 5233-5238 (2011).

13. Yu, F. W., Chan, K. T., Yang, J. \& Sit, R. K. Y. Comparative study on the energy performance of chiller system in an institutional building with stochastic frontier analysis. Energy Build. 89, 206212 (2015).

14. Wei, X., Xu, G. \& Kusiak, A. Modeling and optimization of a chiller plant. Energy 73, 898-907 (2014).

15. Sun, Y., Wang, S., Cui, B. \& Yim, M. S. C. Energy performance enhancement of Hong Kong International Airport through chilled water system integration and control optimization. Appl. Therm. Eng. 60, 303-315 (2013).

16. Hwang, R. L., Yang, K. H., Chen, C. P. \& Wang, S. $\mathrm{T}$. Subjective responses and comfort reception in transitional spaces for guests versus staff. Build. Environ. 43, 2013-2021 (2008).

17. Chun, C., Kwok, A. \& Tamura, A. Thermal comfort in transitional spaces-basic concepts: Literature review and trial measurement. Build. Environ. 39,
1187-1192 (2004).

18. Nicol, J. F., Humphreys, M. \& Roaf, S. Adaptive Thermal Comfort: Principles and Practice [Paperback]. (Routledge, 2012). at $<$ http://www.amazon.co.uk/Adaptive-ThermalComfort-Principles-Practice/dp/0415691591>

19. Jitkhajornwanich, K. \& Pitts, A. Interpretation of thermal responses of four subject groups in transitional spaces of buildings in Bangkok. Build. Environ. 37, 1193-1204 (2002).

20. Roaf, S., Crichton, D. \& Nicol, F. Adapting Buildings and Cities for Climate Change. Adapt. Build. Cities Clim. Chang. (Architectural Press., 2010). doi:10.1016/B978-1-85617-720-7.00007-3

21. Abbaspour, M. . et al. Thermal comfort evaluation in Tehran metro using Relative Warmth Index. Int. J. Environ. Sci. Technol. 5, 297-304 (2008).

22. Ojima, T. and Miura, S. Environmental study on underground shopping center. Urban Underground Utilization. 4th Int. Conf. Undergr. Sp. Earth Shelter. Build. Tokyo 471-477 (1991).

23. Barbhuiya, S. \& Barbhuiya, S. Thermal comfort and energy consumption in a UK educational building. Build. Environ. 68, 1-11 (2013).

24. Humphreys, M. A. Examining and developing the adaptive relation between climate and thermal comfort indoors. in NCEUB 9-11 (Network for comfort and energy used in buildings, 2010). at $<$ http://nceub.commoncense.info/uploads/22-01-05Humphreys.pdf $>$

25. Pitts, A. Thermal Comfort in Transition Spaces. Buildings 3, 122-142 (2013).

26. bin Saleh, J. \& Pitts, A. Potential for Energy Saving in Transition Spaces. Ashrae Stand. (2004).

27. International Code Council. International Energy Conservation Code. (2012). at $<$ http://energytaxincentives.org/uploaded_files/iecc0 9.pdf $>$

28. Jitkhajornwanich, K. Transitional Spaces as a mitigation feature for thermal environments of buildings in hot and humid tropical regions (Part 2). World Renew. Energy Congr. 698-701 (2000).

29. Hancock, J. E. \& Heschong, L. Thermal Delight in Architecture. Jae 33, (MIT Press, 1980).

30. Malchaire, J. Human thermal environments: The effects of hot, moderate and cold environments on human health-comfort and performance: The principles and the practice. Saf. Sci. 18, (CRC Press, 1994).

31. ASHRAE. ASHRAE Standard 140. (2011). at $<$ https://energyplus.net/testing $>$ 